\title{
Commentary: To unilateral, or to bilateral, that is the question
}

\author{
Sung Jun Park, MD, and Joon Bum Kim, MD, PhD
}

\footnotetext{
From the Department of Thoracic and Cardiovascular Surgery, Asan Medical Center, University of Ulsan College of Medicine, Seoul, South Korea.

Disclosures: Authors have nothing to disclose with regard to commercial support

Received for publication July 18, 2019; accepted for publication July 18, 2019; available ahead of print Aug 23, 2019.

Address for reprints: Joon Bum Kim, MD, PhD, Department of Thoracic and Cardiovascular Surgery, Asan Medical Center, University of Ulsan College of Medicine, 88, Olympic-Ro- 43-Gil, Songpa-Gu, Seoul 05505, South Korea (E-mail: jbkim1975@amc.seoul.kr).

J Thorac Cardiovasc Surg 2020;159:2171-2

$0022-5223 / \$ 36.00$

Copyright (c) 2019 by The American Association for Thoracic Surgery

https://doi.org/10.1016/j.jtcvs.2019.07.019
}

Postoperative neurologic deficit is still one of the major concerns in aortic arch surgery, and cerebral protection strategy has been an important focus to prevent this complication. Although antegrade cerebral perfusion (ACP) coupled with moderate hypothermic circulatory arrest has become a more and more favored approach among the contemporary aortic surgeons, there still is no universal consensus to choose between bilateral ACP (bACP) and unilateral ACP (uACP) as the default strategy. ${ }^{1}$ Probably because of ethical and legal constraints in these high-risk arch surgeries, a randomized trial comparing uACP and bACP has yet to be performed, and our practices have therefore had to rely on best evidence from observational studies. Most previous clinical research studies comparing these 2 strategies, including the results from several metaanalyses, have shown comparable results in early mortality and stroke between uACP and bACP. ${ }^{2-5}$ There has been insufficient data, however, on comparative outcomes between the 2 approaches in complex arch procedures requiring prolonged circulatory arrest time. ${ }^{5}$

In the current issue of the Journal, Angleitner and colleagues ${ }^{6}$ have retrospectively compared uACP (93 patients, $50.5 \%$ ) versus bACP (91 patients, $49.5 \%$ ) in the setting of acute type A aortic dissection. Although there were no significant differences in the rates of operative mortality, neurologic deficits, and overall follow-up mortality between $\mathrm{UACP}$ and bACP in the overall cohort, Angleitner and colleagues ${ }^{6}$ found a significantly improved overall survival with $\mathrm{bACP}$ in the subgroup of patients requiring prolonged ACP time ( $\geq 50$ minutes). They infer that such an improved outcome with bACP was attributable to fewer neurologic events in patients with bACP, and consequently they cautiously suggest the preferential use of bACP in surgery for acute type A dissection.

Statistical adjustments with multivariable Cox and propensity score models were conducted in this study. Of note, all measurable variables that may affect decision to

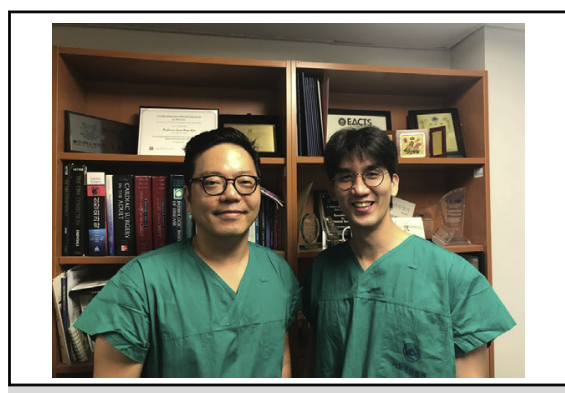

Joon Bum Kim, MD, PhD (left), and Sung Jun Park, $\mathrm{MD}$ (right)

\section{Central Message}

The debate on unilateral versus bilateral cerebral perfusion as a default strategy in arch repair seems to move toward the question of comparative safety for situations requiring long arrest times.

See Article page 2159.

choose one strategy rather than the other were incorporated into the propensity score model, including surgical year and expertise of surgeon (described as the aortic team). Such rigorous baseline adjustments aided in enhancing the robustness of the study conclusion that there were no intergroup differences in overall survival and in secondary outcomes for the entire study cohort.

The results derived from the subgroup analysis, however, could not be fully addressed by rigorous statistical treatments. Rather, they incorporated several decisive variables only in statistical models because of the small sample size of this subset. As a result, the Kaplan-Meier plot in this subgroup with ACP time of at least 50 minutes demonstrated an extraordinarily huge survival divergence, with early death rates of almost $50 \%$ in the uACP group. The size of this divergence, however, may be attributable more to residual selection bias than to the modality of ACP. Of note, this subgroup analysis was conducted with a Cox model incorporating as variables only the cardiopulmonary bypass time and the modality of ACP because of the limited sample size, which may weaken the conclusion in this subgroup.

This study of Angleitner and colleagues ${ }^{6}$ confirms the safety and effectiveness of $\mathrm{UACP}$ relative to bACP in relatively brief arch repairs, and these findings are also supported by previous studies. ${ }^{3-5,7}$ Urbanski and colleagues ${ }^{8}$ also report outstanding outcomes of uACP, with stroke rate ranging from $0.9 \%$ to $1.0 \%$, although the skilled nature 
of the procedures is reflected in the brief mean circulatory arrest time of less than 20 minutes. It is well known that uACP provides technical simplicity for surgeons and allows them to eliminate redundant risks of embolic stroke and further injuries on arch vessels, especially on the left side. Use of uACP may be justified in simple arch procedures, such as hemiarch repair, on the premise of thorough patient selection. Only limited data, however, even including this study of Angleitner and colleagues, ${ }^{6}$ are available to determine the true beneficial role of bACP relative to $\mathrm{UACP}$ in complex and complicated arch repairs. Because bACP occasionally distracts surgeons from straightforward surgical execution and may delay the flow of main procedures, these issues should be considered when bACP is supposed to be undertaken.

Despite several limitations inherent to single-center observational data and a limited sample size of the study by Angleitner and colleagues, ${ }^{6}$ it is clear that this interesting comparison of bACP and uACP will contribute to broadening our perspective in the area of arch surgery and to the accumulation of evidence in this field. Randomized trials may give the best answers to the question of uACP versus bACP in arch surgery; even without randomized trials, however, further studies through large multicenter registry data are expected to give reasonable answers to this question.

\section{References}

1. De Paulis R, Czerny M, Weltert L, Bavaria J, Borger MA, Carrel TP, et al. EACTS Vascular Domain Group. Current trends in cannulation and neuroprotection during surgery of the aortic arch in Europe. Eur J Cardiothorac Surg. 2015;47:917-23.

2. Angeloni E, Benedetto U, Takkenberg JJ, Stigliano I, Roscitano A, Melina G, et al. Unilateral versus bilateral antegrade cerebral protection during circulatory arrest in aortic surgery: a meta-analysis of 5100 patients. J Thorac Cardiovasc Surg. 2014; 147:60-7.

3. Angeloni E, Melina G, Refice SK, Roscitano A, Capuano F, Comito C, et al. Unilateral versus bilateral antegrade cerebral protection during aortic surgery: an updated meta-analysis. Ann Thorac Surg. 2015;99:2024-31.

4. Preventza O, Simpson KH, Cooley DA, Cornwell L, Bakaeen FG, Omer S, et al. Unilateral versus bilateral cerebral perfusion for acute type A aortic dissection. Ann Thorac Surg. 2015;99:80-7.

5. Tian DH, Wilson-Smith A, Koo SK, Forrest P, Kiat H, Yan TD. Unilateral versus bilateral antegrade cerebral perfusion: a meta-analysis of comparative studies. Heart Lung Circ. 2019;28:844-9.

6. Angleitner P, Stelzmueller ME, Mahr S, Kaider A, Laufer G, Ehrlich M. Bilateral or unilateral antegrade cerebral perfusion during surgery for acute type A dissection. J Thorac Cardiovasc Surg. 2020;159:2159-67.e2.

7. Spielvogel D, Kai M, Tang GH, Malekan R, Lansman SL. Selective cerebral perfusion: a review of the evidence. J Thorac Cardiovasc Surg. 2013;145(3 Suppl): S59-62.

8. Urbanski PP, Thamm T, Bougioukakis P, Irimie V, Prasad P, Diegeler A, et al. Efficacy of unilateral cerebral perfusion for brain protection in aortic arch surgery. J Thorac Cardiovasc Surg. February 21, 2019 [Epub ahead of print]. 